\title{
BIOCOMPOSITES FROM ABACA STRANDS AND POLYPROPYLENE: EFFECT OF CHEMICAL TREATMENT BY STEARIC ACID
}

UDC: 678.742 .3

Original scientific paper

https://doi.org/10.18485/aeletters.2020.5.4.3

\author{
Haydar U. Zaman ${ }^{1 *}$, Ruhul A. Khan ${ }^{1}$ \\ ${ }^{1}$ Institute of Radiation and Polymer Technology, Bangladesh Atomic Energy Commission, Savar, P.O. Box \\ 3787, Dhaka, Bangladesh
}

\begin{abstract}
:
Unidirectional composites of polypropylene (PP), reinforced with abaca fiber was fabricated by compression molding with and without the presence of stearic acid (SA) as a coupling agent. Raw abaca fiber was utilized and four levels of filler loading (10, 20, 30 and $40 \mathrm{wt} \%)$ were used during composite manufacturing. Mechanical tests (tensile, bending and impact properties) of the resultant composites were conducted. Based on fiber loading, 30\% fiber-reinforced composites had the optimum set of mechanical properties. Optimized abaca fiber was chemically treated with SA to increase its compatibility with the polymer matrix. SA treated abaca fiber-reinforced composites yielded better mechanical properties compared to the raw composites. In order to know more about the fibermatrix adhesion, scanning electron micrographs (SEM) of the tensile fractured samples showed improved adhesion between abaca and PP matrix upon treatment with SA. Water uptake and simulating weathering test of the composites were also investigated.
\end{abstract}

ARTICLE HISTORY

\author{
Received: 15.11.2020. \\ Accepted: 16.12.2020. \\ Available: 31.12.2020.

\section{KEY WORDS} \\ Abaca fiber, polypropylene, \\ composite, stearic acid and \\ mechanical properties
}

\section{INTRODUCTION}

Composite materials based on natural fiber reinforcement of thermoplastics have been the subject of extensive research and development around the world and are now commercialized, most notably in the automotive industry [1]. Natural fibers, which have good mechanical properties, are relatively inexpensive and are renewable resource of materials throughout the world, especially in tropical region. Because of low density, low cost, renewability, and biodegradability natural fibers can be used as a substitute for synthetic fibers in many respects. In recent years, researcher's interest has focused on the use of natural fibers as reinforcement in polymeric matrix. Considering the environmental aspect, it would be very healthy to use natural fibers instead of synthetic fibers. Natural fibers like jute, cotton, abaca, bamboo, coir, flax, hemp, and sisal have all been proved to be good reinforcement in thermoplastic matrices and being using in automotive applications, construction as well as packaging industries with few drawbacks [2].

Abaca fiber is one of the world's most important natural fibers obtained from the pseudo-stem of the plant (Musa textilis) is a bast fiber and is also known as Manila hemp. It is a member of the Musacea (banana) family of plants. Abaca fiber is a waste product of banana cultivation and without any additional cost input abaca fiber can be obtained for industrial purposes. Table I shows some of the typical properties of abaca fibers [3]. A number of papers have been published on abaca fibers where abaca was used as a reinforcing agent in thermoplastics like polyethylene (PE) and polypropylene PP [4,5]. PP is a class of thermoplastic engineering polymer and it possesses several 
imperative and useful properties such as high vicat softening point, good flex life, sterilizability, good surface hardness, scratch resistance, and good abrasion resistance. PP was chosen as the matrix of the composite because it has low specific density, no environmental pollution when incinerated, and intriguing mechanical properties at low price, and excellent and desirable physical, and thermal properties when used in normal a temperature applications, and takes a large portion in wood plastic composites markets [6, 7].

Table 1. Properties of banana fiber [3]

\begin{tabular}{|c|c|}
\hline Property & Value \\
\hline Density $\left(\mathrm{g} / \mathrm{cm}^{3}\right)$ & 1.35 \\
\hline Elongation at break (\%) & $5-6$ \\
\hline Cellulose content $(\%)$ & $63-64$ \\
\hline Lignin content $(\%)$ & 5 \\
\hline Tensile strength $(\mathrm{MPa})$ & $550 \pm 6.7$ \\
\hline Young's modulus $(\mathrm{GPa})$ & 20 \\
\hline Diameter $(\mu \mathrm{m})$ & $120 \pm 5.8$ \\
\hline Microfibrillar angle $\left({ }^{\circ}\right)$ & 11 \\
\hline
\end{tabular}

Water molecule absorbed by cellulose molecule form cellulose hydrate and the reaction is exothermic, which provide the driving force for further absorption [8]. The high moisture sensitivity of lignocellulosic fiber causes the dimensional instability and limits the use of fiber as reinforcement in composite materials. Low interfacial properties between fiber and polymer matrix often reduce their potential as reinforcing agents due to the hydrophilic nature of natural fibers. The moisture absorbed by the fibers can be reduced by chemical modifications of fibers such as acetylation, mercerization, benzoylation, permanganate treatment $[9,10]$.

Apart from above mentioned coupling agents stearic acid (SA) has also been recognized as coupling agent. The incorporation of SA on the zeolite surface improved the flexibility of polymer matrices. Bellayer et al. [11] also fabricated SAtreated $\mathrm{CaCO}_{3}$-LLDPE composites to study the intumescence mechanism. A comprehensive literature review reveals that $S A$ as a coupling agent for cellulosic fiber composites has not been investigated so far. Hence this study explored the use of SA as the coupling agent for the fabrication of abaca-PP composites. In the present study, a thorough investigation has been carried on the variation of mechanical properties such as tensile, bending and impact properties of abaca fiberreinforced polypropylene composites prepared by compression molding. The effect of the fiber loading on the mechanical properties and morphology of abaca fiber reinforced PP are also reported. Water uptake and simulating weathering test of the composites were also investigated.

\section{EXPERIMENTAL}

\subsection{Materials}

Granules of PP were purchased from the Cosmoplene Polyolefin Company Ltd. (401, Ayer Merbau Road, Singapore), with a density of $0.90 \mathrm{~g} / \mathrm{cm}^{3}$ and a melt flow rate of $14 \mathrm{~g} / 10$ minutes $\left(2.16 \mathrm{~kg}\right.$ at $\left.230^{\circ} \mathrm{C}\right)$ was used as received. Abaca fibers with fiber diameters in the range $0.20-0.25 \mathrm{~mm}$ were obtained from banana-trees collected in Bangladesh was used as filler. Banana is a high herbaceous plant (2-16 $\mathrm{m}$ high), composed of long fibers strongly overlapping forming a pseudo-stem. Banana-trees produce generally 30 large leaves (almost $2 \mathrm{~m}$ long and $30-60 \mathrm{~cm}$ wide). Other chemicals, namely, SA, acetone and toluene were purchased from Aldrich Chemical Co. Inc. (USA). Solvents were used as received.

\subsection{Methods}

\subsubsection{Preparation of composites}

Abaca fibers were neatly separated by hand adhering pith, if any, were removed and the fibers were cut to uniform size of $150 \mathrm{~mm}$ length. The wellseparated fibers were dipped in acetone for half an hour at room temperature for the removal of extraneous matter. The washed samples were dried in air and desired amount was weighed. SA was dissolved in a mixture of toluene and acetone [SA: toluene: acetone in the ratio $1: 10: 10(\mathrm{w} / \mathrm{w} / \mathrm{w})]$. This solution was poured in the aluminum tray containing sparsely spread abaca fibers [SA: abaca fiber in the ratio 1:3 $(\mathrm{w} / \mathrm{w})]$. The tray was covered with aluminum foil and was left to stand for $2 \mathrm{~h}$, after that the solvent mixture was allowed to evaporate at room temperature. SA-coated abaca fibers were also oven dried for $48 \mathrm{~h}$ at a constant temperature of $60^{\circ} \mathrm{C}$. For making one PP sheet, granules of PP (about $6 \mathrm{~g}$ ) was placed into two steel plates and placed into the hot press (Carver, INC, USA, Model 3856). The press was operated at $180^{\circ} \mathrm{C}$. Steel plates were pressed at $7 \mathrm{MPa}$ pressure for $2 \mathrm{~min}$. The plates were then cooled for $3 \mathrm{~min}$ in a separate press under 
$7 \mathrm{MPa}$ pressure at room temperature. The resulting PP sheet was cut into the desired size $(150 \times$ $120 \times 0.25 \mathrm{~mm}^{3}$ ) for composite fabrication. The fibers were then placed unidirectionally between PP sheets, randomly in a mold having dimension $150 \times$ $120 \times 0.25 \mathrm{~mm}^{3}$. Composites were prepared at different fiber loading (say, 10-40 wt\%) by sandwiching four layers of fibers between five layers of pre-weighted PP sheets. Composites were made by pressing this sandwich at $190^{\circ} \mathrm{C}$ for 5 minutes under a pressure of $10 \mathrm{MPa}$. Then the composite sample containing steel plates was cooled to another press (Carver Laboratory Press, USA, Model 2518) operated at cooling condition.

\subsubsection{Mechanical testing}

The tensile and bending properties of the composite samples were determined according to DIN 53455 and DIN 53452 standard methods by a universal testing machine (model H50 KS-0404, Hounsfield Series S, UK). The crosshead speed was $10 \mathrm{~mm} / \mathrm{min}$ and gauge length was $20 \mathrm{~mm}$, whereas for bending measurement span distance was $40 \mathrm{~mm}$. Impact strength (IS) was measured using an impact tester (MT-3016) according to DIN 53433. All the samples were conditioned at $25^{\circ} \mathrm{C}$ and $50 \%$ relative humidity.

\subsubsection{Morphological study}

Tensile fracture surface morphology of the composites with and without SA treatment were observed in a scanning electron microscope (SEM, model JEOL JSM-5310) at $10 \mathrm{kV}$. Before SEM, the samples were coated with a thin layer $(25 \mathrm{~nm})$ of gold under vacuum, using a BAL-TEC SCD 050 Sputter Coater layer to avoid electrical charge accumulation.

\subsubsection{Water uptake of the composites}

Rectangular specimens of dimension $25.4 \mathrm{~mm} \times$ $76.2 \mathrm{~mm}$ were taken for water uptake test as per ASTM D-579-99. The samples were dried by heating in an oven at $50^{\circ} \mathrm{C}$ for about $24 \mathrm{~h}$, subsequently cooled in a desicator and weighed. Finally, all the samples were immersed in a beaker containing 100 $\mathrm{ml}$ of deionised water at room temperature $\left(25^{\circ} \mathrm{C}\right)$ for different time periods (up to 30 days). After certain periods of time; samples were taken out from the beaker and wiped (5 times) using a dry cloth and then their weight was taken again. The samples were placed back in water after each measurement. The weight gained, i.e. water uptake of the samples, was calculated as the weight difference and is reported as percent increase of the initial weight.

\subsubsection{Simulated weathering test}

Both untreated and treated composite samples were subjected to simulated weathering test for 300 $h$, which was performed in alternating cycles of sunlight over $4 \mathrm{~h}\left(65^{\circ} \mathrm{C} \pm 2^{\circ} \mathrm{C}\right)$ using UV lamp $(313 \mathrm{~nm})$ and dews and condensation $2 \mathrm{~h}\left(45^{\circ} \mathrm{C} \pm 2^{\circ} \mathrm{C}\right)$ using a tester (Q-UV-26200, Q-panel Co.). The samples were then dried in the oven for half an hour and weighed, and their mechanical properties were measured. In all of the above-mentioned experiments, at least five separate samples are tested and the experimental results are averaged to get the credible results.

\section{RESULTS AND DISCUSSIONS}

\subsection{Effect of abaca content on the mechanical properties of the composites}

Significant effect of fiber content (wt\%) on the mechanical properties of the composites was measured. Tensile strength (TS) and bending strength (BS) values of untreated abaca fiber composites at different fiber loading are shown in Fig.1. It was found that TS and BS increased with an increase in fiber loading up to $30 \%$; however, for $40 \%$ fiber loaded composites the TS and BS decreased (Fig.1). TS and BS of the untreated composites having $30 \%$ abaca content was found to be 38.3 and $44.1 \mathrm{MPa}$, respectively.

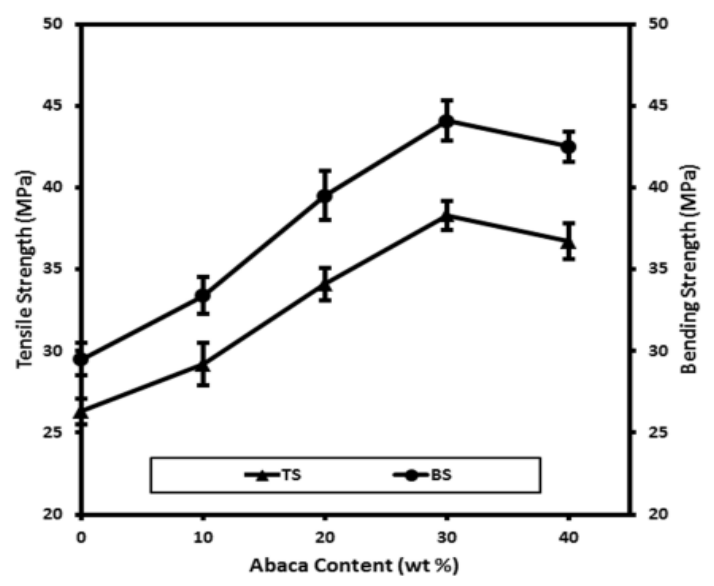

Fig.1. Effect of fiber loading on the tensile and bending strength of abaca fiber/PP composites

The influence of fiber loading on the tensile modulus (TM) and bending modulus (BM) of abaca- 
polypropylene composite was studied and the result is shown in Fig.2. The TM and BM of PP continuously increased with increasing fiber loading from 10 to 40 wt\%. This increase was due to an initial reinforcement effect [12] by the natural fibers, which allowed stress distribution from the continuous polymer matrix to the dispersed fiber phase. The height TM and BM of the composites were found to be 0.84 and $0.88 \mathrm{GPa}$, respectively.

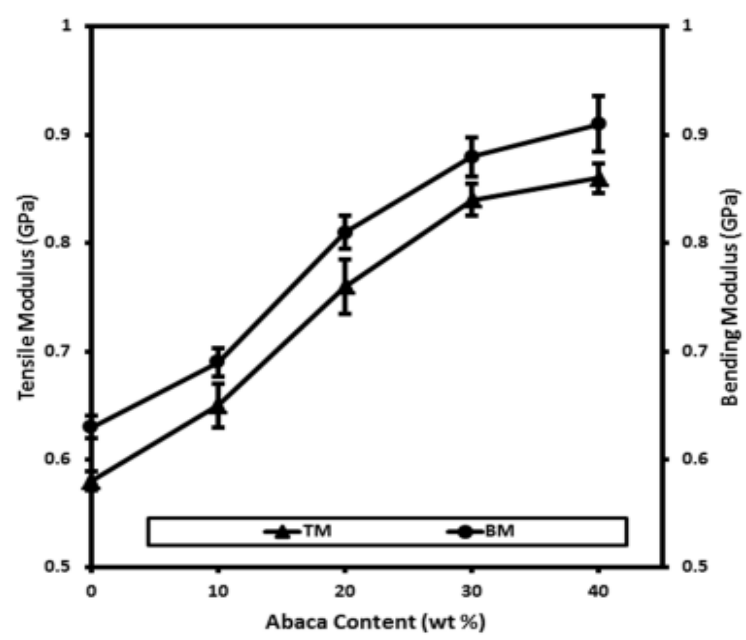

Fig.2. Variation of tensile and bending modulus of abaca fiber/PP composites at different fiber loading

Variation of Charpy impact strength (IS) with fiber loading for untreated abaca fiber reinforced PP composites is shown in Fig.3.

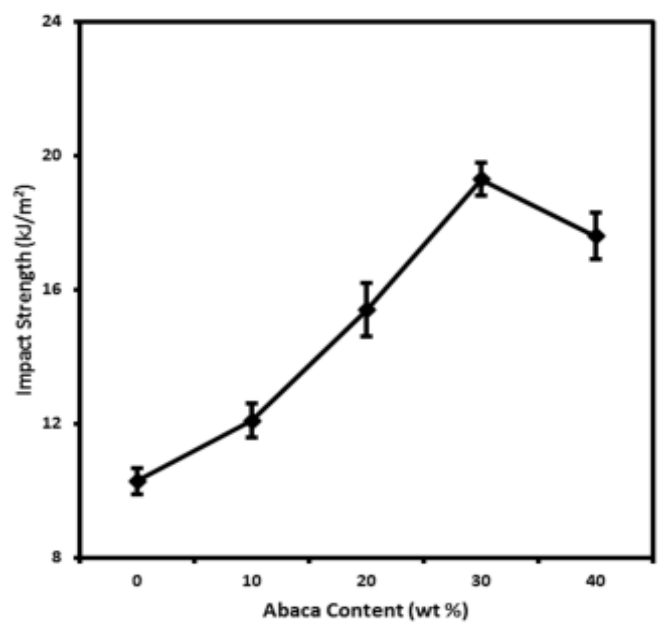

Fig.3. Variation of impact strength of abaca fiber/PP composites at different fiber loading

The IS increased with increasing fiber loading up to $30 \%$; however, $40 \%$ fiber-loaded composites yielded lower IS values compared to the $30 \%$ ones.
At $30 \%$ abaca content in the composite, the height value of IS was found to be $19.3 \mathrm{~kJ} / \mathrm{m}^{2}$. So the composition at $30 \%$ abaca content was taken to be the optimum composition. The TS, BS, TM, BM and IS of the composites at $30 \mathrm{wt} \%$ of abaca fiber loading showed an improvement of $46 \%, 49 \%, 45 \%, 40 \%$, and $184 \%$, respectively, when compared with virgin PP matrix. This increase in the mechanical properties reveals that abaca fibers with uniform cross section and high aspect ratio have the capability to support effective stress transformation from the matrix. At low abaca fiber loading, the extent of improvement in mechanical performance is less when compared with 30 wt\% of abaca fiber loading because at low fiber loading, fiber orientation plays a major role in the performance of the composites. Poor fiber alignment at lower fiber loading results a larger free space for fiber movement thereby reducing the effective stress transfer from fiber to matrix [13]. Furthermore, a minimum critical weight ratio fiber loading is required to reinforce the matrix, hence fiber loading at $10 \mathrm{wt} \%$ may not be suffice to effectively reinforce PP matrix and transfer stress. In this study, 30 wt\% of banana fiber loading is the critical wt\% in which the fibers are sufficient to restrain the matrix leading to uniform stress distribution and offers effective reinforcement to the matrix. However, beyond 30 wt\%, fiber loading decrease in mechanical properties to the tune of $4 \%$, $3.6 \%$, and $9 \%$ in TS, BS and IS was noticed. The decrease in strength at higher fiber loading could be reflection of poor adhesion between the fibers and matrix which promoted microcrack formation at the interface as well as non-uniform stress transfer due to the fiber agglomeration in the matrix [13]. Higher fiber loading also results to the formation of voids in the composites because of fiber-fiber agglomeration due to $\mathrm{H}$-bonding between the fibers leading to nonuniform distribution of fibers within PP matrix results deterioration in mechanical properties. The TM and BM of PP, however, increased consistently with fiber loading from 10 to $40 \mathrm{wt} \%$ thereby revealing reinforcing effect. The impact response in fiber reinforced composites reflects a failure process involving crack initiation and growth in the resin matrix, fiber breakage and pullout, delaminating and disbanding. The increase in notched impact strength can be explained by the fact that the fibers interact with the crack formation and act as stress transferring medium. At high fiber loading of $40 \mathrm{wt} \%$, deterioration in impact strength was observed due to the presence of many fiber ends within the 
composites which could result in crack initiation and hence potential composite failure [14]. A similar explanation of the probability of fiber agglomeration resulted in the regions of stress concentrations that requires less energy to propagate a crack can be explained in the failure of composites.

\subsection{Effect of SA treatment on the mechanical properties of the composites}

The effect of the coupling agent (SA) on the static mechanical properties such as TS, BS, TM, BM and IS of 30 wt\% abaca fiber reinforced PP composites (AFRP) were evaluated and results are graphically presented in Fig. 4 and 5.

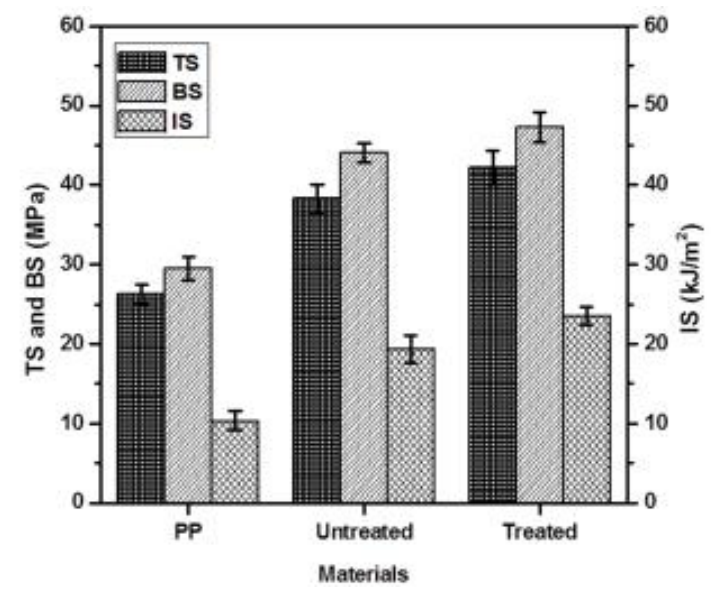

Fig.4. Tensile, bending and impact strength of treated and untreated abaca-PP composites

With the incorporation of SA, a further increase in mechanical properties for all samples when compared with the unidirectional composites without SA at $30 \mathrm{wt} \%$ fiber loading was observed. The maximum TS and BS of 30 wt\% reinforced AFRP at $10 \mathrm{wt} \%$ of SA loading increased to the tune of 10 and $7 \%$, respectively (Fig.4), when compared with 30 wt\% reinforced AFRP without SA. It was found that the highest IS of unidirectional abaca fiber/PP composites increased by $22 \%$ due to SA coating treatment on the fiber surface, when compared to those of the $30 \mathrm{wt} \%$ AFRP composites (Fig.4). On the other hand, as exemplified in Fig.5, the maximum TM and BM of abaca fiber/PP composites improved by approximately 31 and $29 \%$, respectively, were noted due to SA coating treatment on the fiber surface, when compared to those of the AFRP composites at $30 \mathrm{wt} \%$ fiber loading.

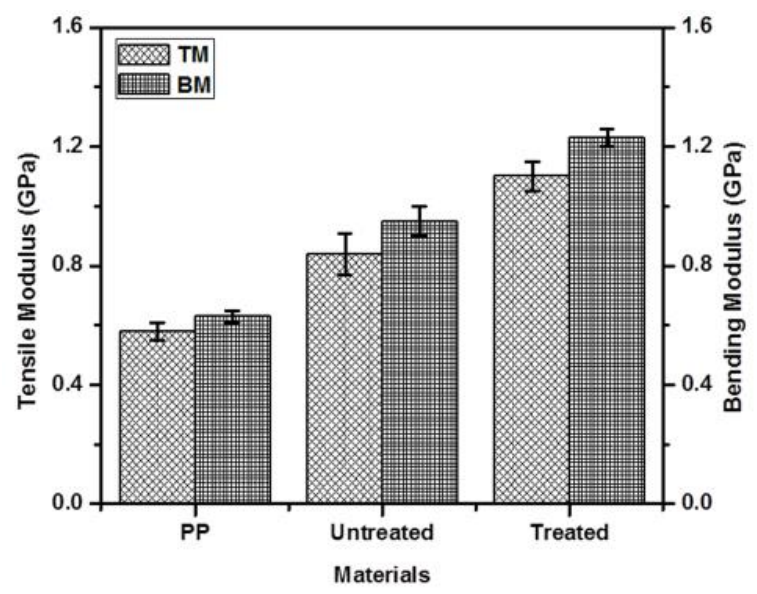

Fig.5. Tensile and bending modulus of treated and untreated abaca-PP composites

The lower mechanical performance of the untreated AFRP composites is mainly due to the presence of hydroxyl and other polar groups in the fiber surface that leads to weak interfacial adhesion between the hydrophilic fiber and hydrophobic PP matrix which results in debonding. However, with the incorporation of SA, the SA interacted with the hydrophilic abaca through its carboxylic group, imparted some extend of hydrophobicity to the abaca surface, thus compatibilizing the abaca with hydrophobic PP. SA in acid form can suitably interact with the fiber surface through acid-base interactions. The improved interaction and adhesion between the fibers and matrix, either through covalent bonding or acid-base interaction (such as $\mathrm{H}$-bonding), or a combination of both, leads to better matrix to fiber stress transfer. SA offers potential covalent bonding between the carboxylic group and hydroxyl groups of the abaca fiber along with chain entanglement between SA and PP chains, creating a good stress transfer at the interface. Bisanda and Ansell [15] also reported that surface treatment of natural fiber improves the adhesive characteristics of abaca fiber by removing the hemicelluloses, thereby producing a rough surface topography which results in improved fiber-matrix interface adhesion and increase in the mechanical properties. However, deterioration in mechanical behavior of the AFRP was observed with the increase in SA weight percent from 10 to 13 wt\% which is mainly ascribed to the self entanglement of SA chains among themselves rather than interaction with the polymer matrix or with fibers, resulting in slippage at the interface which subsequently reduces the mechanical performances [14]. 


\subsection{Morphology of the fractured surface}

Scanning electron micrograph (SEM) of tensile surface of composites samples was taken to understand the fracture mechanism. Examination of the fracture surfaces of the composites by SEM gives information about how a SA affects the interphase of the composites. Fig. 6 ( $a$ and $b$ ) are the tensile fractographs for the untreated and treated composites at $30 \mathrm{wt} \%$ fiber loading.
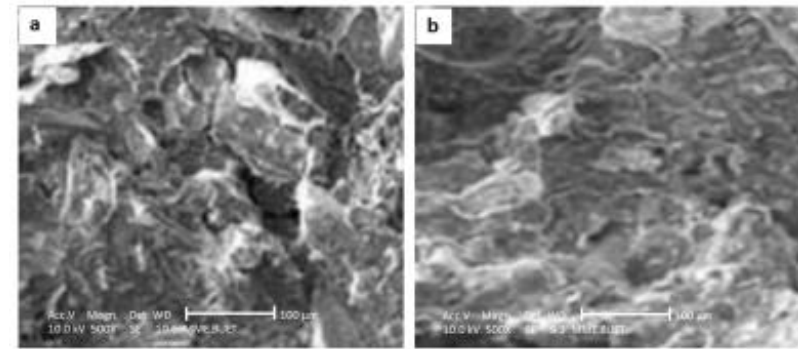

Fig.6. SEM micrograph of the tensile fracture surfaces (30 wt\% fiber loading): (a) untreated abaca fiber composite and (b) SA treated abaca fiber composite

As shown in Fig.6a, poor dispersion was noticed in the untreated fiber composites, where the fibers were seen to agglomerate into bunches and many holes were left after fiber pullout from the matrix on account of the application tensile stress. On the other hand, in treated fiber composites (Fig.6b), improved adhesion and fiber dispersion were seen; this resulted in a lower number of fiber pullouts and voids due to fibers not coming out totally out of the matrix. The fractured surfaces were also more uniformly distributed than in the case of the untreated fiber composites. Lignocellulosic abaca fiber has hydrophilic surface that was treated with SA coating agents, and subsequently used in fabricating unidirectional abaca fiber/PP composites. The interaction between carboxylic group of SA and hydroxyl group (-OH) of abaca took place and caused better adhesion between fiber and matrix. These composites revealed better mechanical properties.

\subsection{Water uptake of the composites}

It is known that lignocellulosic-based composites absorb water causing undesirable dimensional changes in the final product [16]. In addition, water uptake may cause rapid debonding, delamination, and loss of structural integrity [17], leading to deterioration of material mechanical properties. As immersion time in water increases, the composite tensile strength decreases [18]. In water immersion experiments, the extent of water uptake by lignocellulosic-based composites depends strongly on the amount and nature of the lignocellulosic filler. Thus, for composite containing lignocellulosic material such as abaca fiber, an increase in water uptake is expected.

Water uptake characteristics of the manufactured composites against fiber loading are shown in Fig.7. For better comparison, only untreated composite sample and SA treated composite sample are taken.

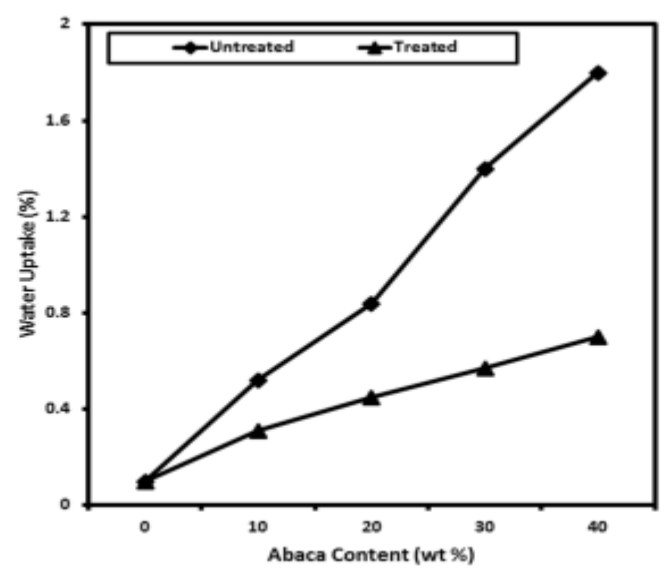

Fig.7. Variation of water uptake of untreated and SA treated abaca fiber/PP composites at different fiber loading

The water uptake (\%) of untreated composite increased with increasing fiber loading up to $40 \mathrm{wt} \%$ [19]. The untreated composite gained a water uptake of about $1.8 \%$ at $40 \mathrm{wt} \%$ fiber loading; whereas SA treated composite sample could soak up about $0.7 \%$. It was observed that the stearic acid pre-treated composites had lower water content compared to the untreated composites. This may be due to the effect of the functional group polarity. Cellulose molecule in virgin abaca fiber contains hydroxyl group, which is polar in nature and absorbs moisture from atmosphere. Whereas stearic acid has carboxylic group which is less polar than hydroxyl group. As a result the pre-treated composites absorbed less water which might improve the dimensional stability of the composites.

\subsection{Simulated weathering effect}

Weathering effect was carried out to investigate the degradation properties in environment. Two composite samples such as untreated and SA treated samples were used to find the effect of weathering on different physical properties. In these respect, both untreated and treated samples were exposed 
to severe weathering test over a period of $300 \mathrm{~h}$ of simulating sunshine and condensation at alternating cycles. In the weathering tester a high-intensity mercury or xenon arc, water spray, and humidity control were used. The loss of tensile properties, particularly TS and TM of the samples were periodically determined. The loss of TS and TM values are presented in Table 2.

Table 2. Degradation of TS TM of untreated and treated composites during simulating weathering tests

\begin{tabular}{|c|c|c|c|}
\hline Materials & $\begin{array}{c}\text { Degradation } \\
\text { time (hr) }\end{array}$ & \multicolumn{2}{|c|}{ Degradation in medium } \\
\hline \multirow{4}{*}{ UAPC } & & LTS (\%) & LTM (\%) \\
\cline { 2 - 4 } & 50 & $6.1 \pm 0.3$ & $7.8 \pm 0.2$ \\
\cline { 2 - 4 } & 100 & $9.6 \pm 0.5$ & $8.9 \pm 0.4$ \\
\cline { 2 - 4 } & 150 & $11.4 \pm 0.7$ & $10.6 \pm 0.6$ \\
\cline { 2 - 4 } & 200 & $13.7 \pm 0.5$ & $12.4 \pm 0.5$ \\
\hline \multirow{4}{*}{ TAPC } & 300 & $14.3 \pm 0.8$ & $13.2 \pm 0.9$ \\
\cline { 2 - 4 } & 50 & $2.2 \pm 0.08$ & $3.7 \pm 0.3$ \\
\cline { 2 - 4 } & 100 & $4.3 \pm 0.09$ & $5.4 \pm 0.4$ \\
\cline { 2 - 4 } & 150 & $6.1 \pm 0.05$ & $6.3 \pm 0.6$ \\
\cline { 2 - 4 } & 200 & $8.2 \pm 0.07$ & $7.1 \pm 0.5$ \\
\hline
\end{tabular}

UAPC: Untreated abaca/PP composite, TAPC: treated abaca/PP composite, LTS: loss of TS (\%), LTM: loss of TM (\%)

The maximum loss TS of untreated sample within the maximum period of observation was about $14.3 \%$, whereas that of the SA treated sample was about $9.1 \%$. Similarly, maximum TM loss was $13.2 \%$, whereas that of the treated sample was $7.9 \%$. The weathering test demonstrated that the untreated samples lost tensile properties (TS and TM), whereas the treated samples retained tensile properties even though these were subjected to severe weathering for $300 \mathrm{~h}$.

\section{CONCLUSIONS}

The mechanical properties of abaca fiber-reinforced PP-based unidirectional composites at various fiber weight percentages were investigated in this study. The research work reported reveals that SA renders hydrophobicity to abaca by coating them and thus makes them compatible with the hydrophobic PP matrix. From the experimental results of this study the following conclusion can be drawn:

1. The TS, BS and IS of the composites increased with increasing fiber loading up to $30 \%$; but TM and $\mathrm{BM}$ of the composites increased consistently with fiber loading from 10 to $40 \%$.

2. The results of mechanical properties showed that the TS, BS, TM, BM and IS values of the treated abaca fiber reinforced composites were higher than those of virgin PP, and even higher than those of raw composites.

3. SEM micrographs of the fracture surface of the composites indicated that the improved tensile properties exhibited by the composites with SA treated abaca fiber could be attributed to structural changes of the fibers as well as to a change in the fiber/matrix interfacial properties in the case of strength.

4. Water uptake behavior of treated composite showed a significantly lower trend relative to untreated composite. Simulated weathering tests demonstrated that the TS and TM of the treated sample could be lower than that of the untreated sample with respect to their degradation time.

\section{REFERENCES}

[1] D. Verma, K.L. Goh, V. Vimal, Interfacial Studies of Natural Fiber-Reinforced Particulate Thermoplastic Composites and Their Mechanical Properties. Journal of Natural Fibers, 7, 2020: 1-28.

https://doi.org/10.1080/15440478.2020.1808 $\underline{147}$

[2] M. Li, Y. Pu, V.M. Thomas, C.G. Yoo, S. Ozcan, Y. Deng, K. Nelson, A.J. Ragauskas, Recent advancements of plant-based natural fiberreinforced composites and their applications. Composites Part B: Engineering, 200, 2020: 108254.

https://doi.org/10.1016/j.compositesb.2020.1 $\underline{08254}$

[3] S. Joseph, M. Sreekala, Z. Oommen, P. Koshy, S. Thomas, A comparison of the mechanical properties of phenol formaldehyde composites reinforced with banana fibres and glass fibres. Composites Science and Technology, 62 (14), 2002: 1857-1868.

https://doi.org/10.1016/S02663538(02)000982

[4] S. Radoor, J. Karayil, S. Rangappa, S. Siengchin, J. Parameswaranpillai, A review on the extraction of pineapple, sisal and abaca fibers and their use as reinforcement in polymer matrix. eXPRESS Polymer Letters, 14 (4), 2020: 309-335.

https://doi.org/10.3144/expresspolymlett.202 $\underline{0.27}$ 
[5] G.S. Krishnan, R. Pradhan, G.B. Loganathan, Investigation on Mechanical Properties of Chemically Treated Banana and Areca Fiber Reinforced Polypropylene Composites, Advances in Lightweight Materials and Structures, Vol.8, Springer, 2020, pp.273-280. https://doi.org/10.1007/978-981-15-7827$4 \quad 27$

[6] H. Chandekar, S. Waigaonkar, V. Chaudhari, Effect of chemical treatment on creep-recovery behavior of jute-polypropylene composites. Proceedings of the Institution of Mechanical Engineers, Part L: Journal of Materials: Design and Applications, 1464420720963344, 2020. https://doi.org/10.1177/1464420720963344

[7] M. Rokbi, A. Khaldoune, M. Sanjay, P. Senthamaraikannan, A. Ati, S. Siengchin, Effect of processing parameters on tensile properties of recycled polypropylene based composites reinforced with Jute fabrics. International Journal of Lightweight Materials and Manufacture, 3 (2), 2020: 144-149. https://doi.org/10.1016/j.ijlmm.2019.09.005

[8] A. Bledzki, A. Mamun, M. Lucka-Gabor, V. Gutowski, The effects of acetylation on properties of flax fibre and its polypropylene composites. Express Polymer Letters, 2 (6), 2008: 413-422.

https://doi.org/10.3144/expresspolymlett.200 8.50

[9] H.U. Zaman, R.A. Khan, Acetylation used for natural fiber/polymer composites. Journal of Thermoplastic Composite Materials, 2019: 121.

https://doi.org/10.1177/0892705719838000

[10] G. Rajeshkumar, An experimental study on the interdependence of mercerization, moisture absorption and mechanical properties of sustainable Phoenix sp. fibre-reinforced epoxy composites. Journal of Industrial Textiles, 49 (9), 2020: 1233-1251.

https://doi.org/10.1177/1528083718811085

[11] S. Bellayer, E. Tavard, S. Duquesne, A. Piechaczyk, S. Bourbigot, Mechanism of intumescence of a polyethylene/calcium carbonate/stearic acid system. Polymer Degradation and Stability, 94 (5), 2009: 797803.

https://doi.org/10.1016/j.polymdegradstab.20 09.01.032
[12] Y. Patil, B. Gajre, D. Dusane, S. Chavan, S. Mishra, Effect of maleic anhydride treatment on steam and water absorption of wood polymer composites prepared from wheat straw, cane bagasse, and teak wood sawdust using Novolac as matrix. Journal of Applied Polymer Science, 77, 2000: 2963-2967. https://doi.org/10.1002/10974628(20000923)77:13<2963::AIDAPP20>3.0.CO;2-0

[13] A.C. Karmaker, A. Hoffmann, G. Hinrichsen, Influence of water uptake on the mechanical properties of jute fiber-reinforced polypropylene. Journal of Applied Polymer Science, 54 (12), 1994: 1803-1807. https://doi.org/10.1002/app.1994.070541203

[14] F.A. Abdul Azam, Z. Razak, M.K.F. Md Radzi, N. Muhamad, C.H. Che Haron, A.B. Sulong, Influence of Multiwalled Carbon Nanotubes on the Rheological Behavior and Physical Properties of Kenaf Fiber-Reinforced Polypropylene Composites. Polymers, 12 (19), 2020: 2083.

https://doi.org/10.3390/polym12092083

[15] E. Bisanda, M.P. Ansell, The effect of silane treatment on the mechanical and physical properties of sisal-epoxy composites. Composites Science and Technology, 41 (2), 1991: 165-178. https://doi.org/10.1016/0266-3538(91)90026L

[16] L.Y. Mwaikambo, E. Martuscelli, M. Avella, Kapok/cotton Fabric-Polypropylene Composites. Polymer Testing, 19, 2000: 905918.

http://hdl.handle.net/20.500.11810/2332

[17] L. Jiang, G. Hinrichsen, Flax and cotton fiber reinforced biodegradable polyester amide composites, 2. Characterization of biodegradation. Die Angewandte Makromolekulare Chemie, 268 (1), 1999: 18-21. https://doi.org/10.1002/(SICI)15229505(19990701)268:1<18::AIDAPMC18>3.0.CO;2-T

[18] I. Danjaji, R. Nawang, U. Ishiaku, H. Ismail, Z.M. Ishak, Degradation studies and moisture uptake of sago-starch-filled linear low-density polyethylene composites. Polymer Testing, 21 (1), 2002: 75-81. https://doi.org/10.1016/S01429418(01)00051-4 
[19] H.-S. Yang, H.-J. Kim, H.-J. Park, B.-J. Lee, T.-S. Hwang, Water absorption behavior and mechanical properties of lignocellulosic filler- polyolefin bio-composites. Composite structures, 72 (4), 2006: 429-437.

https://doi.org/10.1016/i.compstruct.2005.01. $\underline{013}$ 